\title{
RATIONALIZATION OF INTERNAL TRANSPORT OPERATION IN THE INTERMODAL TRANSPORT TERMINAL
}

This paper presents the results of investigation of the possibilities for creating the internal circuit for the handling and moving the containers on the territory of intermodal transport terminal. It utilizes the theoretical knowledge from the investigation of queuing systems and the theory of stochastic processes.

Keywords: Logistics, intermodal transport terminal, transhipment, container, stochastic processes.

\section{Introduction}

The internal operation of the intermodal transport terminal is ensured by the transhipment handling equipment and vehicles of road, railway and waterway transport. In smaller terminals, the intermodal transport units (ITU)s may be transhipped from the railway wagon (or from the ship) directly to semi-trailers that are transported by the trucks to the shipper. During the collection of the ITUs, the direction of the transportations from the shippers to the terminal is opposite. During the rush hour, or at a time when the semi-trailers are not available, the ITUs are unloaded to the storage area from where they are subsequently re-loaded on vehicles and transported to the shippers. Inside the terminal, the internal traffic is not separated from the outside traffic. In larger terminals, ITUs (during the distribution) may be transhipped from the wagon (or from the ship) to the paved surface. Subsequently, they are transported, using the specialized transportation equipment of internal circuit (usually the reachstacker, forklift truck, semi-trailer, straddle stacker or articulated vehicle), to the area served by the road vehicle (usually the articulated vehicle) of the external circuit. In this terminal, the operation is specialized for the handling and transport equipment in order to avoid the congestion caused by the arrival and departure of the external circuit vehicles. The queuing theory may be utilized for the purpose of theoretical basis for solving the issue of determining the marginal boundary for creating the internal circuit for handling and transportation of ITUs within the intermodal transport terminal [1].

The terminal represents the certain kind of queuing systems. In our case, we processed the issue of containers transhipment (re-loading) between the wagons and articulated vehicles. For transhipment, each device has its own specific performance and is able to perform the required container transhipment in a certain time interval. The value of this time interval may vary according to the different circumstances of the operational situation. Arrival of individual road vehicles is a random stochastic process. The question arises: "How we can describe the input traffic flow of these vehicles to the place of operation?" Containers transhipment is the requirement incoming randomly and individually to the system in a certain time interval with a value "t". However, the activity of the whole system, in addition to the arrivals of requirements, is determined by the time interval (period) of their operation and subsequent departure from the system as well. Therefore, the status of the system can theoretically be characterized by the number of requirements " $\mathrm{X}(\mathrm{t})$ ", which are in the system at the time " $t$ ", whether they are operated by the channels (the transhipment handling equipment in our case), or waiting for the operation in the queue [2].

If we consider the random arrivals and random operation period, then "X $(\mathrm{t})$ " is the random variable for the firm " $\mathrm{t}$ " and the activity of the whole queuing system characterizes the random process " $[\mathrm{X}(\mathrm{t}) / \mathrm{t} \geq 0]$ ".

For the particular realization of this process, the function " $\tilde{X}$ " randomly acquires the entire non-negative values so how the requests arrive and depart randomly.

Addiction of random variable "X ( $\mathrm{t}$ )" from the values of previous random variables can be expressed by the conditional probability in the form:

$$
P\left(X(t)=k / X\left(s_{n}\right)=j_{n}, \quad X\left(s_{n-1}\right)=j_{n-1}, \ldots ., X\left(s_{1}\right)=j_{1}\right),
$$

\footnotetext{
* Marian Sulgan, Jarmila Sosedova

Faculty of Operation and Economics of Transport and Communications, Department of Water Transport University of Zilina, Slovakia

E-mail: marian.sulgan@fpedas.uniza.sk
} 
where: " $k, j_{1}, j_{2}, \ldots, j_{n}$ " is a nonnegative number, " $n$ " is a positive number and " $s_{i}<t$ for: $i=1,2, \ldots ., n$ ".

In order to apply the theoretical knowledge properly, it is necessary to have the correct classification of the queuing system. The queuing system is briefly and clearly characterized by a combination of letters and numbers in the form "A / B / C", introduced by D. G. Kendall. Letters that determine the stochastic process describing the arrival of requirements and the distribution of operating time are at the positions A and B. C is a natural number expressing the number of operation channels. Letters at the positions $\mathrm{A}$ and $\mathrm{B}$ are derived from the distinctive feature of the distribution of intervals between the successive arrivals and the operation periods.

The most commonly used letters are:

M - exponential distribution (Markov's attribute)

D - deterministic intervals and operation periods,

$\mathrm{E}_{\mathrm{k}}$ - Erlang distribution with the parameter $\mathrm{k}$,

$\mathrm{G}$ - optional distribution.

In addition, the designation is usually accompanied by other information, such as: "What is the discipline in a queue?"; "Is the number of requirements in the system limited or not (and hence the length of the queue)?" Disciplines of the waiting time may be as follows:

FIFO - first requirement is served as the first (front),

LIFO - last requirement is served as the first (inverse front),

SIRO - service (operation) is in random order,

PRI - service is realized by the preference (priority queue),

GD - optional discipline of the waiting.

This extended designation does not concern the departure of the requirement from the system after the accomplishing the service (operation). If the number of these requirements in the system is constant, these are designated as queuing systems. In practice, the ideal state is not always reachable where each physical present articulated vehicle comes to the terminal in the loaded state (carrying either loaded or empty container) and leaves the terminal in the loaded state. We did not take into consideration the arrivals and departures of solo trucks, because it would be the different system in switching the semi-trailers. In our particular case, the arrival of requirements is regular, that means, that the probability of arriving the " $\mathrm{k}$ " requirements in interval "t" does not depend on its beginning, but only on its length [3].

That means: "P $(\mathrm{N}(\mathrm{s}+\mathrm{t})-\mathrm{N}(\mathrm{s})=\mathrm{k})=\mathrm{P}(\mathrm{N}(\mathrm{t})=\mathrm{k})$ "; for each: " $\mathrm{s} \geq 0$ and $\mathrm{t}>0$ ".

The number of arrivals in any interval with the length " $\mathrm{t}$ " has the same distribution as the "N(t)", therefore, "N(t)" could be understood as the number of arrivals in interval with the length "t". Such processes are called homogeneous.

For homogeneous processes, it can be demonstrated that there exists the limit: $\lim _{t \rightarrow 0} \frac{1-p(t)}{t}=\lambda \geq 0$, where $\lambda$ is a parameter of a homogeneous process.

In a very short time period, the probability of arrival more than one requirement is negligible. That means:

$\lim _{t \rightarrow 0} \frac{P(N(t) \succ 1)}{t}=0$,

what can be written as:

$\lim _{t \rightarrow 0} \frac{1-p_{0}(t)-p_{1}(t)}{t}=0$.

Such processes are called ordinal and, in practice, represent the individual arrival of the requirements.

The arrivals of requirements are independent of each other [4]. If the parameter of the Poisson process is " $\lambda$ ", then the periods of intervals between the successive arrivals will be independent random variables and will have an exponential distribution with the same parameter " $\lambda$ ". If the requirement arrives into the system at the time when the channel is busy, it will stay in a queue and wait for the operation, and the length of the queue will not be limited.

The operating time of each requirement has the exponential distribution with the parameter $\mu$ and is independent of the operation times of other requirements, as well as the intervals between the arrivals. If " $\lambda$ " is the average value of the number of arriving requirements per unit of time, then " $1 / \mu$ " will represent the average value of operating time of each requirement. Then, the channel will be able to serve " $\mu$ " requirements per unit of time and the " $\mu$ " will equal the intensity of service.

In the time interval of " $T$ ", on average, " $\lambda \mathrm{T}$ " of requirements will come and the channel will be able to serve up to " $\mu \mathrm{T}$ " of requirements. It is obvious that in the case that " $\lambda<\mu$ ", the channel will be able to serve all arriving requirements. However, in the case that " $\lambda>\mu$ ", the situation will be opposite. The equality " $\lambda=\mu$ " represents a very tense situation, when the channel cannot be idle for awhile, in order to serve all arriving requirements. The relationship between " $\lambda$ " and " $\mu$ " is expressed by the formula: " $\rho=\frac{\lambda}{\mu}$ ", where: " $\rho$ " is the load factor of the channel (the ratio between the number of incoming requirements and the number of requirements which the channel is able to serve).

In the case that " $\rho>1$ ", then the system will be overloaded. In the case that " $\rho \leq 1$ ", then the average total operating time of the requirements (which will arrive in the time interval of "T") will be " $\lambda T(1 / \mu)$ ".

Compared to the overall time period "T", the channel is in activity " $(\lambda \mathrm{T}(1 / \mu)) / \mathrm{T}=\rho$ ". Load factor will express the working period of the system $\mathrm{T}$ when the channel is in the activity. Then, " $\rho$ " is called the coefficient of utilization of the channel. In practice, so-called Non-Markovian systems with the unlimited queue often appear. For them, the input flow of the requirements has the Markovian characteristics, but the distribution of the operating time is optional - this system is designated as " $\mathrm{M} / \mathrm{M} / 1$ ". 
In more detail, this analysis is focused on the system "M/G/1". After the " $\mathrm{n}$ th" requirement leaving from the system, the number of requirements will remain " $\mathrm{X}$ ". Given the independence of the operating time period on the arrival of requirements, the number of requirements is independent on " $\mathrm{n}$ " and it is designated as a "Y".

Then:

$X_{n+1}=X_{n}+Y$, for $X_{n}=0$.

" $\mathrm{n}$ th" leaving requirement keeps just "Xn $>0$ " requirements in the system. After the requirement leaving, " $(\mathrm{n}+1)^{\mathrm{th}}$ " operation of the subsequent requirement selected from the queue will beggin.

After the " $(n+1)^{\mathrm{th}}$ " requirement leaving, just " $X_{n}-1$ " requirements will remain in the system. These requirements were already in the system during the " $\mathrm{n}$ th" requirements leaving. Plus, the number of requirements arriving during " $(\mathrm{n}+1)^{\mathrm{th}}$ " requirements operation is " $\mathrm{Y}$ "; thus:

$X_{n+1}=X_{n}-1+Y$; for each: $X_{n}>0$.

By introducing the random variable " $\delta$ ", the relationships (3) and (4) can be expressed with a single formula:

$X_{n+1}=X_{n}-\delta+Y$.

Variable " $\delta$ " depends on the variable " $\mathrm{X}$ " as follows: $\delta=0$, if $X_{n}=0, \delta=1$, if $X_{n}>0$. On the basis of the formula (5), the average number of requirements in the system in steady state can be determined. Then, the following formula can be applied: $E\left(X_{n+1}\right)=E\left(X_{n}\right)$.

After the calculation of the average values of both sides of the formula (5), it can be stated:

$E\left(X_{n}\right)=E\left(X_{n}\right)-E(\delta)+E(Y) ; E(\delta)=E(Y)$.

From the definition of the random variable "Y", it is clear that "E $(Y)$ " is the average number of requirements arrivals during the operating time period of one requirement. Again, the operaion time is a random variable that can be designated as " $U$ " and it is expected that it has a finite average value "E (U)" and the dispersion " $\mathrm{D}(\mathrm{U})=\delta^{2}$ ".

If the intensity of arrivals is " $\lambda$ ", then:

$\mathrm{E}(\mathrm{Y})=\lambda \mathrm{E}(\mathrm{U})=\rho$.

where: " $\rho$ " is the load factor of the system. The random variable " $\delta$ " has only two values 0 and 1 ; its average value is therefore: " $E$ $\left.(\delta)=0 . P(\delta=0)+1 . P(\delta=1)=0 . P\left(X_{n}=0\right)+1 . P\left(X_{n}>0\right)-P\right]$ $\left.\mathrm{X}_{\mathrm{n}}>0\right)$ ).

It expresses the probability that the channel is occupied. It is the coefficient of the channel itilization " $\rho$ ". Again, it is required so that " $\rho<1$ ".
As for the the task of finding " $\mathrm{E}(\mathrm{X})$ ", if both sides of the formula (5) are squared, then we will get: " $X_{n+1}^{2}=X_{n}^{2}+\delta^{2}+Y^{2}-2 X_{n} \delta+2 X_{n} Y-2 \delta Y$ ".

The definition of random variable " $\delta$ " is " $\delta$ " $=\delta$ " and " $X_{n} \delta$ $=\mathrm{X}_{\mathrm{n}}$ ". Then, after the transition to the average values, we get: $" E\left(X_{n+1}^{2}\right)=E\left(X_{n}^{2}\right)+E\left(\delta^{2}\right)+E\left(Y^{2}\right)-2 E\left(X_{n}\right)+$ $+2 E\left(X_{n} Y\right)-2 E(\delta Y) "$.

The random variables " $\mathrm{X}_{\mathrm{n}}$ ", the number of requirements which are left in the system by the " $\mathrm{n}$ "th" served requirement " $Y$ "

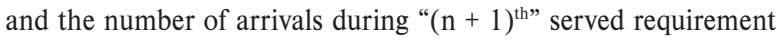
are independent. Then, the last two average values of the multiplied random variables are the same as the multiple of the average values of these variables.

In the steady state, it is applied: " $0=\mathrm{E}(\delta)+\mathrm{E}\left(\mathrm{Y}^{2}\right)-2 \mathrm{E}\left(\mathrm{X}_{\mathrm{n}}\right)+$ $+2 \mathrm{E}\left(\mathrm{X}_{\mathrm{n}}\right) \mathrm{E}(\mathrm{Y})-2 \mathrm{E}(\delta) \mathrm{E}(\mathrm{Y})$ ”. And using the formulas (6) and (7), it can be expressed " $E\left(X_{n}\right)$ " in the form:

$E\left(X_{n}\right)=\rho+\frac{E\left(Y^{2}\right)-\rho}{2(1-\rho)}$.

Since, the process of the arrivals has the Poisson distribution, it can be proved that:

$E\left(Y^{2}\right)=\int_{0}^{\infty} E\left(Y^{2} / u\right) a(u) d u=$

$\int_{0}^{\infty}\left(\lambda^{2} u^{2}+\lambda u\right) a(u) d u=\rho^{2}+\rho+\lambda^{2} \delta^{2}$.

Then, from the formula (8), it can be expressed: “ $E\left(X_{n}\right)=\rho+\frac{\rho^{2}+\lambda^{2} \delta^{2}}{2(1-\rho)}$. This formula expresses the average number of requirements in the system, not only during the departures time periods of requirements, but also, the average number of requirements in any time. And therefore, the following formula can be applied: $L=\rho+\frac{\rho^{2}+\lambda^{2} \delta^{2}}{2(1-\rho)}$. The first member is the average number of served requirements, and the second member is the average length of the queue:

$Q=\frac{\rho^{2}+\lambda^{2} \delta^{2}}{2(1-\rho)}$

where:" $Q$ " is the average number of requirements waiting in the queue, " $\delta$ " is the dispersion of handling time (operation).

Both of these variables increase in proportion with the dispersion of the operating time " $\mathrm{d}$ ".

\section{The proposal of the marginal boundary for creating the internal circuit of the articulated vehicles operation}

On the territory of intermodal terminal, articulated vehicles may be intended not only for collection and distribution of the 
ITUs, but also, for all other operations inside the terminal. These activities may be considered to be an obstacle within the fulfilling the main objective - the high quality of the collection and distribution of intermodal transport units (ITUs).

It is necessary to determine these circumstances and boundary when it is necessary to allocate one, two, or even more trucks (articulated vehicles) for operation within the internal circuit. This boundary can be determined from the comparison of idle times of trucks within the external circuit in the queue (if the internal circuit is not operated) with a total operating time of trucks operating within the internal circuit [5].

If the cumulative idle time of the trucks within the external circuit does not exceed the time period expressed by the active operating time of one truck, operating within the internal circuit, then the creation of internal circuit will be ineffective. Within this research, based on the theoretical knowledge, the creation of internal circuit for average idle time of requirements in the queue (10) of the single-line queuing system was verified.

It is expected that the entry of requirements for handling (operation) has the character of the Poisson distribution. The following relationship is applied: " $\rho=\frac{\lambda}{\mu}$ ”. If variable " $\tau$ " is used instead of " $\frac{1}{\mu}$ ”, then " $\rho=\lambda \tau$ ”, and after its substituting into the formula $(10)$, the following form of the furmula will be determined:

$Q=\frac{\lambda^{2} \tau^{2}+\lambda^{2} \delta^{2}}{2 \cdot(1-\lambda \tau)}=\frac{\lambda^{2}\left(\tau^{2}+\delta^{2}\right)}{2(1-\lambda \tau)}$,

where: " $\tau$ " is the average value of handling during the operation, " $\mu$ " is the number of requirements that can be served by the channel per time unit.

In the particular surroundings of the intermodal transport terminal [6], one requirement represents one operation of the handling equipment (transhipment of the container from railway wagon to semi-trailer, or vice versa). Two requirements represent the physical presence of one semi-trailer in the terminal. The container on the semi-trailer arrives into the terminal, and subsequently, it is transhipped (re-loaded) to the railway wagon. Then, another container is transhipped from the railway wagon to this semi-trailer.

Essentially, transhipment time (operating time of one requirement) generates the certain dispersion around the average value due to a number of specific operating conditions. In theory, it can be concluded that the value of this dispersion is in range of "p" \% around the standard (average) value for the particular device (equipment).

Thus, the dispersion can be expressed as follows: " $\delta=p \cdot \tau$ ”, " $p$ " is the percentage deviation of the handling actual time from the average value (expressed in decimal form, not in percentage).

Value " $\rho=\lambda . \tau$ " represents the load of one operating line. Then, the utilization of the transhipment equipment according to its fluctuating operating time represents a boundary for establishing the internal circuit. The individual values are shown in the following Table 1 .

If " $\delta^{2}=0$ ", it will be idealization - each of the handling times will be considered to be constant. This inaccuracy is partly compensated by the assumption of the Poisson input flow of requirements. Actually, it may be expected that the input is slightly more balanced compared to the previous state. From the aforementioned, the simplified formula may be determined:

“ $\bar{\gamma}=\frac{\lambda \tau^{2}}{2 \cdot(1-\lambda \tau)}$,

where: " $\bar{\gamma}$ " - the average value of idle time related to one requirement in the queue.

The average idle time of one requirement in the queue " $\bar{\gamma}$ "can be obtained from the fraction: " $\bar{\gamma}=\frac{Q}{\lambda}$ ". If " $\lambda$ " is the average number of requirements entering the system per hour,

The marginal number of transhipped ITUs per one day (non-zero dispersion of the handling time during the operation)

Table 1

\begin{tabular}{|c|c|c|c|c|c|c|c|c|}
\hline $\begin{array}{c}\text { Handling } \\
\text { time }\end{array}$ & \multicolumn{3}{|c|}{$\begin{array}{c}\text { Daily working } \\
\text { time in the terminal }\end{array}$} & \multicolumn{2}{|c|}{$\begin{array}{c}\text { Dispersion of the handling time } \\
\text { during the operation }\end{array}$} & $\begin{array}{c}\text { Load of one } \\
\text { operating line }\end{array}$ & $\begin{array}{c}\text { The average number of } \\
\text { handling operations per } \\
\text { minute }\end{array}$ & $\begin{array}{c}\text { The marginal number } \\
\text { of transhipped ITUs } \\
\text { per day }\end{array}$ \\
\hline$\tau$ & & $\mathrm{P}$ & & $\tau+\mathrm{p}$ & $\rho$ & $\lambda$ & ITUs per day \\
\hline & $\mathrm{h}$ & $\mathrm{min}$ & $\%$ & $\mathrm{Min}$ & $\mathrm{min}$ & $\%$ & $1 / \mathrm{min}$ & \\
\hline 4 & 16 & 960 & 0 & 0 & 4 & 82.84 & 0.207 & 99 \\
\hline 4 & 16 & 960 & 1 & 0.04 & 4.04 & 73.21 & 0.183 & 88 \\
\hline 4 & 16 & 960 & 2 & 0.08 & 4.08 & 66.67 & 0.167 & 80 \\
\hline 4 & 16 & 960 & 3 & 0.12 & 4.12 & 61.80 & 0.155 & 74 \\
\hline 4 & 16 & 960 & 4 & 0.16 & 4.16 & 57.98 & 0.145 & 70 \\
\hline 4 & 16 & 960 & 5 & 0.2 & 4.2 & 54.86 & 0.137 & 66 \\
\hline 4 & 16 & 960 & 10 & 0.4 & 4.4 & 44.80 & 0.112 & 54 \\
\hline 4 & 16 & 960 & 25 & 1 & 5 & 32.28 & 0.081 & 39 \\
\hline 4 & 16 & 960 & 50 & 2 & 6 & 24.36 & 0.061 & \\
\hline
\end{tabular}

Source: authors 
then " $\lambda / 2$ " will be the average number of trucks entering the system per hour. If the internal circuit is not in operation, then the total average idle time of the trucks in queue per hour will be in the form: " $\lambda / 2 \cdot \bar{\gamma}$ ".

The existence of a truck in the internal circuit represents one "truck-hour" per hour. If " $\lambda / 2 \cdot \bar{\gamma}$ " does not exceed the value 1 , the creation of the internal circuit is unfounded. The marginal value of " $\lambda$ " can be achieved by calculating the condition: " $\frac{\lambda}{2} \cdot \bar{\gamma}=1$ ". After the substituting and its modification, " $\rho^{2}\left(1+p^{2}\right)=4(1-\rho)$ " can be obtained. And after the subsequent modification, the following quadratic formula can be obtained: " $\left(1+p^{2}\right) \rho^{2}+4 \rho-4=0$, $\rho_{1,2}=\frac{-4 \pm \sqrt{16+4\left(1+p^{2}\right) \cdot 4}}{2\left(1+p^{2}\right)}=\frac{-2 \pm 2 \sqrt{2+p^{2}}}{1+p^{2}}$, The positive root of this formula determines the searched marginal value:

“ $\rho_{1}=\frac{-2+2 \sqrt{2+p^{2}}}{1+p^{2}}$,

Let us denote " $\rho=\lambda . \tau$ ", then the formula " $\rho^{2}+4 \rho-4=0$ " will be created and its positive root will have the value: " $\rho=-2+2 . \sqrt{2}=0.828428$ ". If the formula " $\rho=\lambda . \tau$ " is considered to be the load of one operating line of the single-line system, then the utilization of transhipment equipment approximately at the level of $83 \%$ will represent the marginal boundary for the establishment (creation) of the internal circuit.

\section{Conclusion}

If the transhipment equipment, which operates with the average handling time during the operation at the level of " $\tau$ " $=4$ minutes, is utilized within the terminal, then, from the condition " $4 \lambda=0.828428$ ", the marginal value " $\lambda=0.207$ " handling operations per minute will be calculated.

That represents the number of 158,976 operations per working day ( 960 minutes) and 99 of ITUs per day. As for this value, the reduction of idle times of trucks in the queue equals the performance of one truck, which will be extra deployed.

If the number of transhipped ITUs in the terminal is, on average, higher than 99 of ITUs per day, then the trucks deployment for the internal circuit will represent the savings in work shifts of the trucks.

In this case, the creation of the internal circuit is well founded. Table 2 contains the marginal number of transhipped ITUs per one day.

The aforementioned considerations are related to a specific value of handling time during the operation equal to 4 minutes. Table 2 shows the calculated values of the marginal number of transhipped ITUs per one day (and the dispersion of the handling time during the operation is at the level of " 0 ") for the handling times in the range of 1-10 minutes.

The marginal number of transhipped ITUs per one day

Table 2

\begin{tabular}{|c|c|c|c|c|c|c|}
\hline $\begin{array}{c}\text { Handling } \\
\text { time }\end{array}$ & \multicolumn{2}{|c|}{$\begin{array}{c}\text { Daily working } \\
\text { time in the terminal }\end{array}$} & $\begin{array}{c}\text { Dispersion of the } \\
\text { handling time during } \\
\text { the operation }\end{array}$ & $\begin{array}{c}\text { Load of one } \\
\text { operating line }\end{array}$ & $\begin{array}{c}\text { The average number of handling } \\
\text { operations per minute }\end{array}$ & $\begin{array}{c}\text { The marginal number of } \\
\text { transhipped ITUs per day }\end{array}$ \\
\hline$\tau$ & & $\mathrm{P}$ & $\rho$ & $1 / \mathrm{min}$ & ITU per day \\
\hline & $\mathrm{h}$ & $\min$ & $\%$ & $\%$ & 0.828 & 398 \\
\hline 1 & 16 & 960 & 0 & 82.84 & 0.414 & 199 \\
\hline 2 & 16 & 960 & 0 & 82.84 & 0.276 & 133 \\
\hline 3 & 16 & 960 & 0 & 82.84 & 0.207 & 99 \\
\hline 4 & 16 & 960 & 0 & 82.84 & 0.184 & 80 \\
\hline 4.5 & 16 & 960 & 0 & 82.84 & 0.166 & 66 \\
\hline 5 & 16 & 960 & 0 & 82.84 & 0.138 & 61 \\
\hline 6 & 16 & 960 & 0 & 82.84 & 0.127 & 57 \\
\hline 6.5 & 16 & 960 & 0 & 82.84 & 0.118 & 50 \\
\hline 7 & 16 & 960 & 0 & 82.84 & 0.104 & 44 \\
\hline 8 & 16 & 960 & 0 & 82.84 & 0.092 & 40 \\
\hline 9 & 16 & 960 & 0 & 82.84 & 0.083 & \\
\hline 10 & 16 & 960 & 0 & 82.84 & & \\
\hline
\end{tabular}

Source: authors 
Considering the previous calculations, it can be concluded that the values of marginal number of transhipped ITUs per one day are most influenced by selecting the particular type of handling (transhipment) equipment and the number of such equipment within the intermodal transport terminal.

\section{Acknowledgements}

This paper presents the results of work supported by the Slovak Scientific Grant Agency of the Slovak Republic under the project VEGA 1/0331/14: Modelling of Distribution Logistics System with Using Software Solutions. Faculty of Operation and Economics of Transport and Communications, University of Zilina.

\section{References}

[1] PALUCH, S., PESKO, S.: Quantitative Methods in Logistics, Monography, EDIS - Zilinska univerzita, 2007, 185 p. ISBN 80-8070636-0.

[2] DAVID, A.: Innovation of Handling Systems in the World Container Ports and their Terminals, Proc. of $17^{\text {th }}$ intern. conference: Transport means 2013, October 2013, pp. 250-253, Kaunas University of Technology, ISSN 1822-296X.

[3] KUBASAKOVA, I., KAMPF, R., STOPKA, O.: Logistics Information and Communication Technology, Communications - Scientific Letters of the University of Zilina, No. 2, 2014, pp. 9-13, ISSN 1335-4205.

[4] KUBASAKOVA, I., BUKOVA, B.: Logistics Systems and Technologies in Praxis, EDIS : Zilinska univerzita, 2012, CD-ROM, 211 p., ISBN 978-80-554-0595-7.

[5] GASPARIK, J., STOPKA, O., PECENY, L.: Quality Evaluation in Regional Passenger Rail Transport, Nase More, vol. 62, No. 3, 2015, pp. 114-118. ISSN 0469-6255.

[6] SIMKOVA, I., KONECNY, V., LISCAK, S., STOPKA, O.: Measuring the Quality Impacts on the Performance in Transport Company, Transport Problems, vol. 10, No. 3, 2015, pp. 113-124, ISSN 1896-0596. 